\title{
ESCALA DIAGRAMÁTICA PARA AVALIAÇÃO DA SEVERIDADE DE BACTERIOSE EM PESSEGUEIRO ${ }^{1}$
}

\author{
IDEMIR CITADIN ${ }^{2}$, ANDRÉ PAULO ASSMANN $^{3}$, SERGIO MIGUEL MAZARO $^{4}$, \\ ALFREDO DE GOUVÊA ${ }^{4}$, MOESES ANDRIGODANNER ${ }^{5}$, GUSTAVO MALAGI ${ }^{3}$
}

RESUMO - Uma escala diagramática para quantificar a severidade da bacteriose em folhas de pessegueiro (Prunus persica), causada por Xanthomonas arboricola pv. pruni, foi desenvolvida e validada. A escala considerou os limites de severidade mínima e máxima da doença observados no campo, e os níveis intermediários seguiram incrementos logarítmicos, obedecendo-se à"Lei do estímulo de Weber-Fechner". A escala consta de seis níveis: 0,$5 ; 1,5 ; 4,3 ; 12,0 ; 29,1$ e 55,3\%, sendo avaliada por sete indivíduos sem experiência na avaliação da bacteriose em pessegueiro. Inicialmente, a estimativa da severidade foi feita sem auxílio da escala em 50 folhas com diferentes níveis de severidade. Em seguida, os mesmos avaliadores utilizaram a escala diagramática proposta. Por meio de regressão linear, confrontando-se valores de severidade reais e estimados, analisaram-se a acurácia e a precisão dos avaliadores. Constataramse acurácia e precisão das estimativas visuais efetuadas com o auxílio da escala diagramática. A escala diagramática proposta foi considerada adequada para estimar a severidade de bacteriose em pessegueiro, podendo ser utilizada para estudos epidemiológicos e de avaliação de estratégias de controle desta doença.

Termos para indexação: patometria, severidade.

\section{DIAGRAMATIC SCALE TO EVALUATE THE SEVERITY OF BACTERIOSE IN PEACH TREES}

ABSTRACT - A diagrammatic scale was developed and validated to assess the severity of the bacteriose in peach leaves, caused by Xanthomonas arboricola pv. pruni. The scale was elaborated considering the maximum and minimum limits of disease severity observed in the field and the intermediate levels followed logarithmic increments according to the "Stimulus Law by Weber-Fechner". The scale presents six levels of disease severity $(0,5 ; 1,5 ; 4,3 ; 12,0 ; 29,1$ and $55,3 \%)$ which validation was carried out by seven individuals without previous practice in evaluating of the bacteriose in peach trees. Initially the estimates of severity were performed without the use of the scale in 50 leaves with different levels of severity. Then, the appraisers estimated the severity of the same leaves previously assessed using the proposed diagrammatic scale. Accuracy and precision were determined by linear regression, relating real and estimated severity values. The scale provided good levels of accuracy and precision of visual estimates. The proposed diagrammatic scale was considered adequate to the bacteriose severity in peach trees and it can be used in epidemiological studies and on evaluation for controlling this disease.

Index terms: pathometry, severity

\section{INTRODUÇÃO}

A bacteriose em pessegueiro, causada por Xanthomonas arboricola pv. pruni, é considerada uma das principais doenças da cultura, infectando folhas, ramos e frutos, podendo comprometer a produtividade principalmente quando as condições climáticas são favoráveis para a sua ocorrência (Fortes \& Martins, 1998). Nas folhas, os sintomas iniciais são manchas angulares, de aspecto aquoso, de $1-3 \mathrm{~mm}$, com halo amarelado. Com o tempo, a lesão aumenta de tamanho, formando uma necrose de coloração púrpura ou preta que,mais tarde,se desprende do limbo foliar, deixando a folha perfurada (May De Mio et al., 2004).

A quantificação de uma variável que expresse a incidência e a severidade da doença é importante para descrever o progresso das epidemias e sua relação com o clima ou com medidas de controle, bem como para validação de modelos de previsão ou aplicação do manejo integrado (Sposito et al., 2004) como já demonstrado por vários autores em estudos de outros patossistemas (Diaz et al., 2001; Leite \& Amorim, 2002; Rodrigues et al., 2002; Gomes et al., 2004; Halfeld-Vieira, 2006; Mazaro et al., 2006). Erros na quantificação da doença podem resultar em uma análise epidemiológica incorreta subseqüente, interferindo nas conclusões alcançadas. Para que sejam minimizados os erros, o método utilizado para quantificação de doenças deve ser capaz de fornecer resultados acurados, precisos e reproduzíveis (Sposito et al., 2004).

Nesse sentido, a escala utilizada por pesquisadores no Brasil para quantificação de bacteriose é a proposta por Zehr et

'(Trabalho 164-07). Recebido em: 03-07-2007. Aceito para publiação em: 17-03-2008.

${ }^{2}$ Engenheiro Agrônomo, Professor, Doutor, UTFPR - Câmpus Pato Branco, Via do conhecimento, Km 01, 85501-970, Pato Branco, Paraná idemir@utfpr.edu.br.

${ }^{3}$ Estudante de Agronomia, bolsista PIBIC/CNPq, UTFPR - Câmpus Pato Branco, andrebalisa@yahoo.com.br. malagi.gustavo@gmail.com. ${ }^{4}$ Engenheiro Agrônomo, Professor, Doutor, UTFPR - Câmpus Dois Vizinhos. sergio@utfpr.edu.br; alfredo@utfpr.edu.br.

${ }^{5}$ Eng. Agrônomo, Mestrando Programa de Pós-Graduação em Agronomia da UTFPR, moesesandrigo@yahoo.com.br. 
al. (1996); no entanto, essa apresenta deficiência, pois foi desenvolvida em condições edafoclimáticas diferentes das brasileiras, além de não ter considerado os incrementos logarítmicos de severidade perceptíveis pela visão humana.

Dessa forma, o objetivo deste trabalho foi desenvolver uma escala diagramática para avaliação da severidade da bacteriose em pessegueiro para as condições edafoclimáticas do Paraná, com padronização e validação para ser empregada em trabalhos epidemiológicos.

\section{MATERIAL E MÉTODOS}

Para a elaboração da escala diagramática,foram colhidas 300 folhas de diversas seleções de pessegueiro cultivadas na área experimental da Universidade Tecnológica Federal do Paraná - Câmpus Pato Branco-PR, no ano de 2007. As folhas apresentavam diferentes níveis e tamanhos de áreas lesionadas pela bacteriose. As áreas lesionadas foram copiadas em lâminas de transparência, e suas dimensões, bem como as dimensões das folhas foram determinadas por meio do medidor de área foliar, marca LI-COR ${ }^{a}$ modelo 3100 . Considerou-se a máxima e a mínima proporção de área foliar lesionada como sendo os valores máximo e mínimo da escala diagramática. Os quatro níveis intermediários foram definidos matematicamente, seguindo incremento logarítmico e respeitando-se a acuidade da visão humana de acordo com a Lei do estímulo de Weber e Fechner (Horsfall \& Barrat, 1945).

Uma vez definidas a percentagem de área foliar lesionada e seus correspondentes níveis a serem adotados na escala, uma folha de tamanho médio, com formato-padrão e área conhecida, foi reproduzida seis vezes, representando os sintomas de cada nível, procurando-se manter os padrões de distribuição das lesões.

Para a validação da escala diagramática proposta, foram tomadas 50 folhas com diferentes níveis de severidade e apresentadas para sete avaliadores sem experiência prévia na avaliação de doenças, que estimaram a severidade de bacteriose numa primeira etapa sem e, posteriormente,com a escala diagramática.

A acurácia e a precisão das estimativas visuais de cada avaliador foram determinadas por regressão linear simples, considerando a severidade real como variável independente e a severidade estimada como variável dependente. A precisão das estimativas foi avaliada pelo coeficiente de determinação da regressão $\left(r^{2}\right)$ e pela variância dos erros absolutos (severidade estimada menos severidade real).

\section{RESULTADOS E DISCUSSÃO}

A escala diagramática proposta neste trabalho (Figura 1) possui seis níveis de severidade $(0,5 ; 1,5 ; 4,3 ; 12,0 ; 29,1$ e 55,3\%) e obedeceu à "Lei do estímulo de Weber-Fechner", conforme descrito em trabalhos anteriores de elaboração de escalas (Michereff et al., 2000; Diaz et al., 2001; Leite \& Amorim, 2002;
Rodrigues et al., 2002; Martins et al., 2004 e Mazaro et al., 2006). O máximo da proporção da área foliar lesada encontrado foi de $55,3 \%$, discordando do proposto por Zehr et al. (1996), que obtiveram $75 \%$. Nas condições em que foi desenvolvido este trabalho, observou-se a queda das folhas, quando a área lesionada se situava acima dos 55,3\%.

Na validação da escala diagramática, todos os avaliadores mostraram boa acurácia, pois os valores estimados de severidade ficaram próximos dos valores da severidade real, sendo claramente observado quando se compararam as linhas de regressão entre severidade real e estimada, sem escala (Figura 2, A-G) e com escala (Figura 2, H-N). O uso da escala mostrou-se eficiente na melhoria da acurácia dos avaliadores 3;4;5 e 7, quando se compararam as linhas de regressão entre severidade real e estimada, sem e com escala, com valores próximos entre os estimados e os valores reais,o que determina a acurácia das avaliações (Bergamim Filho \& Amorim, 1996).

A precisão é um fator a ser considerado na validação de uma escala diagramática, e é definida como a exatidão de uma operação onde há rigor ou refinamento na medida (Bergamim Filho \& Amorim, 1996). A precisão pode ser avaliada por meio do coeficiente de determinação da regressão, que deve ser próximo de $100 \%$, e pela variação dos erros absolutos (diferença entre severidade estimada e real). Com a utilização da escala diagramática proposta para a bacteriose em pessegueiro, os avaliadores apresentaram boa precisão, com coeficiente de determinação entre 0,73 e 0,86 ; sem o uso da escala, esse valor ficou de 0,64 a 0,80 (Tabela 1), indicando que,com o uso da escala, as estimativas foram sistematicamente relacionadas com o valor real. Para todos os avaliadores, ocorreu aumento do coeficiente de determinação de regressão quando se fez uso da escala.

Além do coeficiente de correlação, a boa precisão dos avaliadores foi observada com a determinação do erro absoluto ou resíduo, ou seja, a diferença entre a severidade estimada e a real. Os valores obtidos de resíduos podem ser considerados bons, pois a maior parte permaneceu dentro dos valores aceitáveis $(-10$ a +10$)$, segundo critérios adotados por programas de computadores para treinamento na quantificação de doenças, como Distrain (Tomerlin \& Howell, 1988) e Disese.Pro (Nutter Jr. $\&$ Worawitlikit, 1989). Quando se compara o grupo de avaliadores sem escala (Figura 2, A-G) com o grupo com escala (Figura 2, H$\mathrm{N})$, percebe-se que de modo geral o erro diminuiu em todos os avaliadores. Os avaliadores 1 e 3 que subestimavam, e os avaliadores $4 ; 5 ; 6$ e 7, que superestimavam a severidade da doença, diminuíram significativamente seus erros quando se utilizaram da escala, demonstrando a boa eficiência da mesma para quantificar, de forma mais precisa, a bacteriose em pessegueiro. Os avaliadores 6 e 7, mesmo com utilização da escala, tiveram tendência a superestimar a doença, caso que pode ser melhorado com o seu treinamento prévio. 

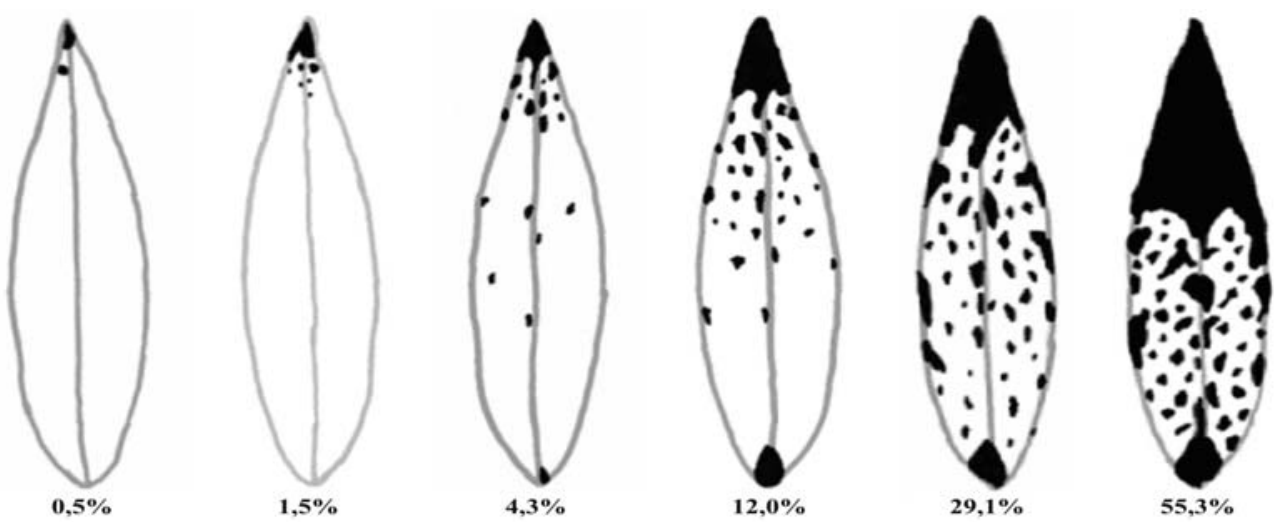

FIGURA 1 - Escala diagramática para avaliação da severidade de bacteriose em pessegueiro causada por Xanthomonas arboricola pv. pruni. Valores em porcentagem da área foliar com sintomas. UTFPR - Câmpus Pato Branco, 2007.

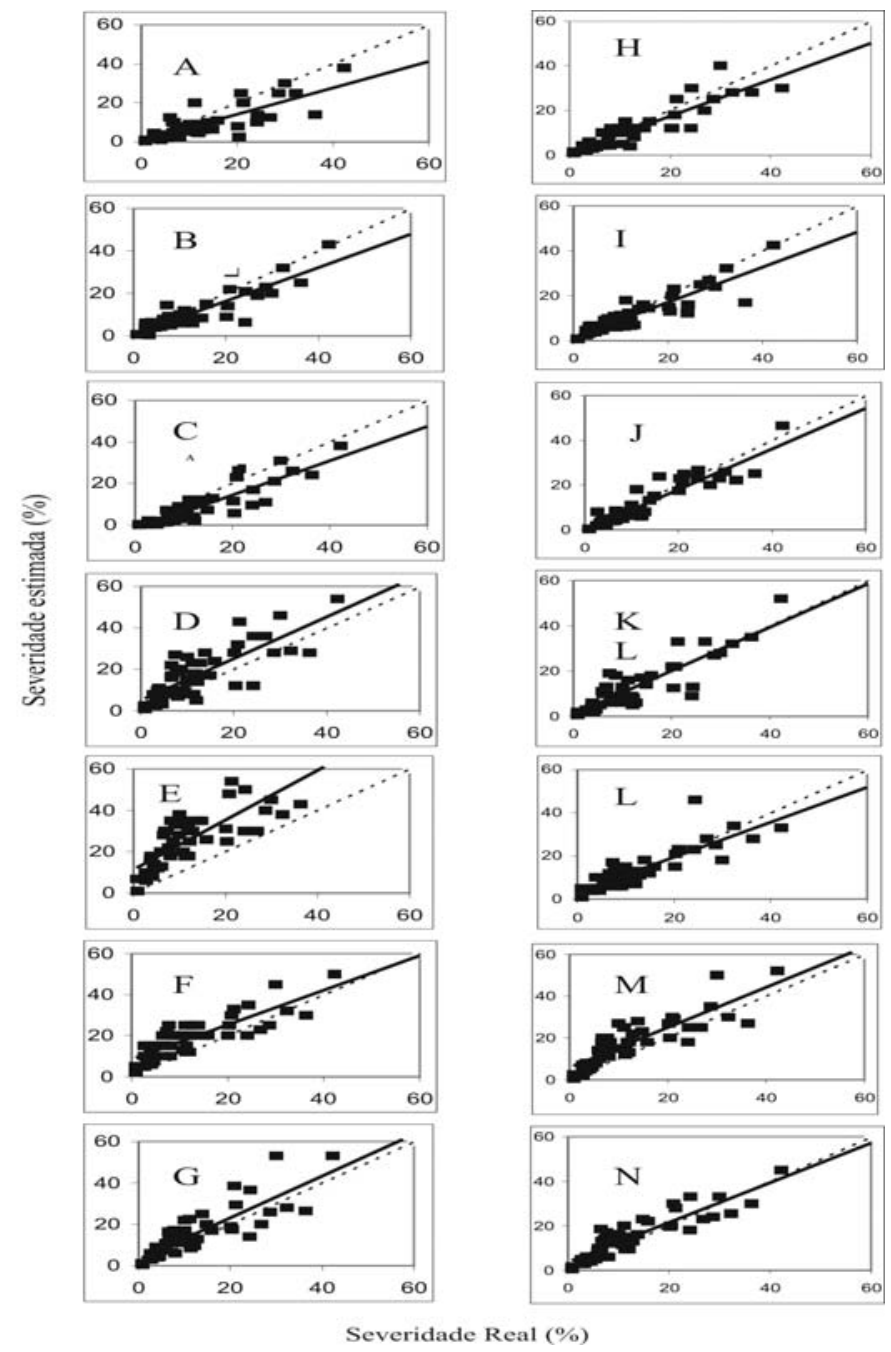

FIGURA 2 - Severidade estimada (pontos cheios) por seis avaliadores: avaliador $1(\mathrm{~A}, \mathrm{H}) ; 2(\mathrm{~B}, \mathrm{I}) ; 3(\mathrm{C}, \mathrm{J})$; 4(D,K); 5(E,L); 6(F,M); 7 (G,N), sem auxílio (A-G) e com auxílio (H-N), da escala diagramática e linhas de regressão obtida entre severidades reais e estimadas (linhas cheias). A linha pontilhada representa a situação ideal, com as estimativas idênticas à real. UTFPR - Câmpus Pato Branco, 2007

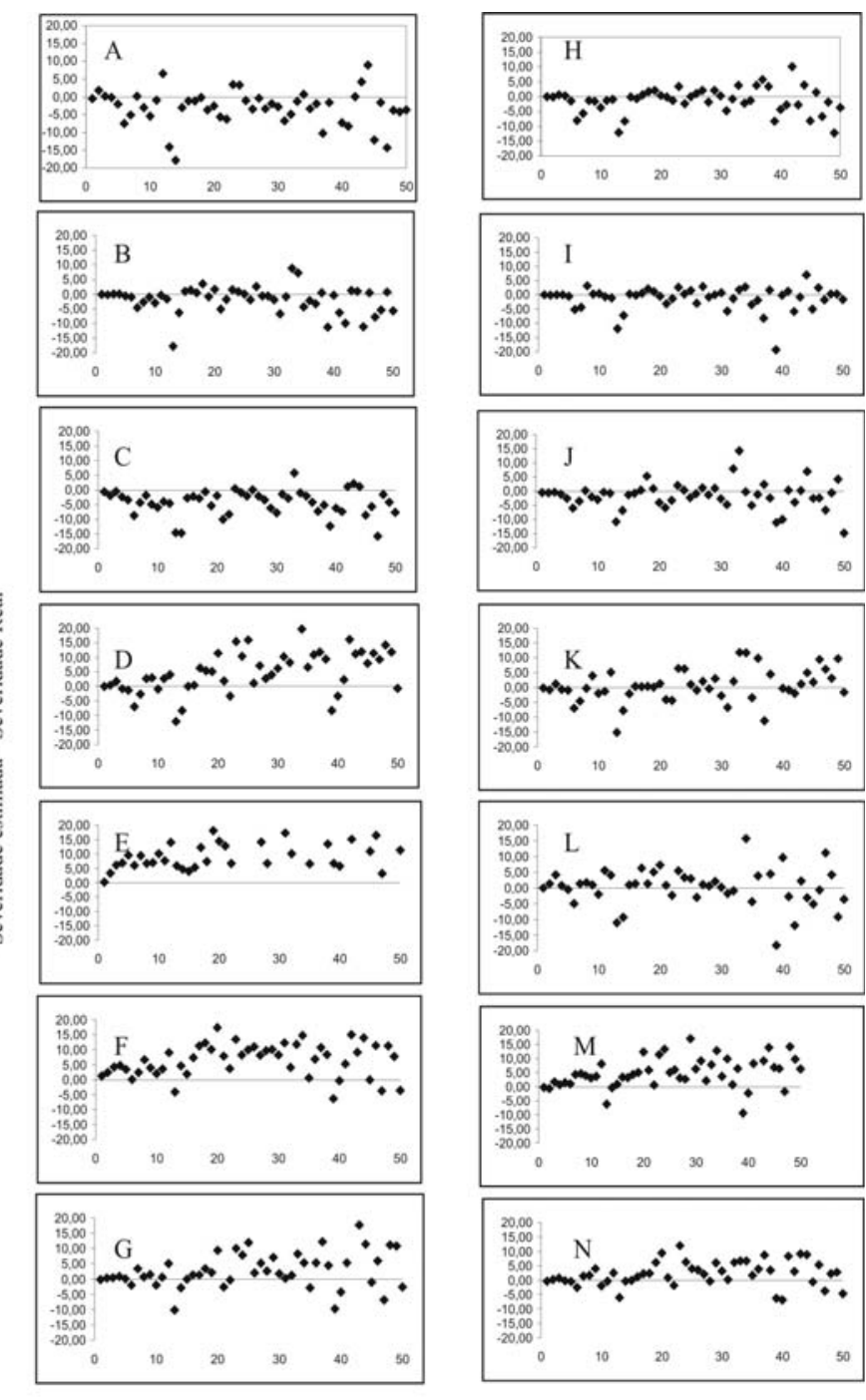

Severidade Real $(\%)$

FIGURA 3 - Erros absolutos (severidade real menos severidade estimada) das estimativas da severidade de bacteriose em pessegueiro, por sete avaliadores: 1(A,H);2(B,I);3(C,J); 4(D,K); 5(E,L); 6(F,M); 7 (G,N), sem (A-G) e com (H-N) auxílio de escala diagramática. UTFPR - Câmpus Pato Branco, 2007. 
TABELA 1- Avaliação dos coeficientes lineares (a), coeficientes angulares (b) e coeficientes de correlação ( $\left.\mathrm{R}^{2}\right)$ obtidos nas regressões entre severidade real (variável independente) e severidade estimada (variável dependente) de 50 folhas de pessegueiro atacados por Xanthomonas arborícola pv. pruni, segundo sete avaliadores sem e com a utilização da escala diagramática proposta. UTFPR-Câmpus Pato Branco, 2007.

\begin{tabular}{|c|c|c|c|c|c|c|}
\hline \multirow[t]{2}{*}{ Avaliador } & \multicolumn{3}{|c|}{$\begin{array}{l}\text { Sem } \\
\text { escala }\end{array}$} & \multicolumn{3}{|c|}{$\begin{array}{l}\text { Com } \\
\text { escala }\end{array}$} \\
\hline & $a$ & b & $r^{2}$ & $a$ & b & $r^{2}$ \\
\hline 1 & 0,5653 & 0,6768 & 0,6612 & 0,965 & 0,8184 & 0,8068 \\
\hline 2 & 0,7602 & 0,7851 & 0,7828 & 1,4921 & 0,7779 & 0,8193 \\
\hline 3 & 2,0652 & 0,8254 & 0,8017 & 0,0174 & 0,9041 & 0,8621 \\
\hline 4 & 4,9866 & 1,0071 & 0,6408 & 0,7923 & 0,9616 & 0,7674 \\
\hline 5 & $11,36 \quad 2$ & 1,1976 & 0,6653 & 3,2479 & 0,8105 & 0,7348 \\
\hline 6 & 8,4756 & 0,8394 & 0,7108 & 5,7234 & 0,959 & 0,736 \\
\hline 7 & 2,9983 & 1,006 & 0,7066 & 3,5251 & 0,8941 & 0,8183 \\
\hline
\end{tabular}

\section{CONCLUSÃO}

A utilização da escala diagramática para bacteriose em pessegueiro permite quantificar os sintomas da doença de forma acurada e precisa. Seu uso em estudos epidemiológicos, de resistência genética e de manejo da doença, proporcionará informações mais adequadas sobre Xanthomonas arboricola pv. pruni em pessegueiro.

\section{REFERÊNCIAS}

BERGAMIN FILHO, A.; AMORIM, L. Doenças de plantas tropicais: epidemiologia e controle econômico. São Paulo: Agronômica Ceres, 1996. 299p.

DIAZ, C. G.; BASSANEZI, R.B.; FILHO, A.B. Desenvolvimento e validação de uma escala diagramática para Xanthomonas axonopodis pv. phaseoli em feijoeiro. Summa Phytopatologica, Botucatu, v.27, n.7, p.35-39, 2001.

FORTES, J.F.; MARTINS, O.M. Sintomatologia e controle das principais doenças. In: MEDEIROS, C.A.B.; RASEIRA, M.do C.B. (Ed.). A cultura do pessegueiro. Pelotas: Embrapa-CNPACT, 1998. p.243-264.

GOMES, A.M.A.; MICHEREFF, S.J.; MARIANO, R.L.R. Elaboração e validação de escala diagramática para cercosporiose da alface. Summa Phytopathologica, Botucatu, v.30, n.1, 2004.

HALFELD-VIEIRA, B.; NECHET, K.L. Elaboração e validação de escala diagramática para avaliação da mancha-de-cercospora em melancia. Fitopatologia Brasileira, Brasília, v.31, n.1, p.46-50, 2006.

HORSFALL, J. C.; BARRATT R. W. Na improved gradig system for measuring plant diseases. Phytopathology, St Paul, v.35, p.665, 1945.

LEITE, R.M.V.B.C.; AMORIM, L. Elaboração e validação de escala diagramática para Mancha de Alternária em girassol. Summa Phytopathologica, Botucatu, v. 28, p. 14-19, 2002.
MARTINS, M.C.; GUERZONI, R.A.; CÂMARA, G.M.S.; MATTIAZZI, P.; LOURENÇO, S.A.; AMORIM, L. Escala diagramática para a quantificação do complexo de doenças foliares de final de ciclo em soja. Fitopatologia Brasileira, Brasília, v.29, n.2, p.179-184, 2004.

MAY DE MIO, L.L.; GARRIDO, L.; UENO, B. Doenças de fruteiras de caroço. In: Monteiro, L.B.; May de Mio, L.L.; Serrat, B.M.; Motta, A.C.; Cuquel, F.L. (Ed.). Fruteiras de caroço: uma visão ecológica, Curitiba: Universidade Federal do Paraná, 2004. p.169222

MAZARO, S.M.; GOUVÊA, A.; MIO, L.L.M; DESCHAMPS. C.; BIASI, L.A.; CITADIN, I. Escala diagramática para avaliação da severidade da mancha-de-micosferela em morangueiro. Ciência Rural, Santa Maria, v.36, n.2, p.648-652, 2006.

MICHEREFF, S. J.; MAFFIA, L.A.; NORONHA, M.A. Escala diagramática para avaliação da severidade da queima das folhas do inhame. Fitopatologia Brasileira, Brasília, v.25, n.4, p.612$619,2000$.

NUTTER Jr., F.W.; WORAWITLIKIT, O. Disease.Pro: a computer program for evaluating and improving a person ability to assess disease proportion. Phytopathology, St Paul, v.79, p. 1135, 1989 (abstract).

RODRIGUES, J. C. V.; NOGUEIRA, N. L.; MACHADO, M. A. Elaboração e validação de escala diagramática para leprose dos citros. Summa Phytopathologica, Botucatu, v. 28, p. 192-196, 2002.

SPOSITO, M.B.; AMORIM, L.; BELASQUE JUNIOR, J.; BASSANEZI, R.B.; AQUINO, R. Elaboração e validação de escala diagramática para avaliação da severidade da mancha preta em frutos cítricos. Fitopatologia Brasileira, Brasília, v.29, n.1, p.81$85,2004$.

TOMERLIN, Jr.; HOWELL, T.A. Distrain: a computer program for training people to estimate disease severity on cereal leaves. Plant Disease, St Paul, v.72, p.455-459, 1988.

ZEHR, E.I.; SHEPARD, D.P.; BRIDGES, W.C. Bacterial spot of peach as influenced by water congestion, leaf wetness duration and temperature. Plant Disease, St Paul, v.80, p.339-341-, 1996. 